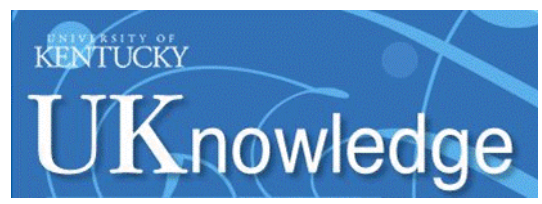

University of Kentucky

UKnowledge

3-5-2021

\title{
The Origins of Religious Disbelief: A Dual Inheritance Approach
}

Will M. Gervais

Brunel University London, UK

Maxine B. Najle

University of Kentucky, maxine.najle@uky.edu

Nava Caluori

University of Virginia

Follow this and additional works at: https://uknowledge.uky.edu/psychology_gradpub

Part of the Psychology Commons, and the Religion Commons

Right click to open a feedback form in a new tab to let us know how this document benefits you.

\section{Repository Citation}

Gervais, Will M.; Najle, Maxine B.; and Caluori, Nava, "The Origins of Religious Disbelief: A Dual Inheritance Approach" (2021). Psychology Graduate Research. 1.

https://uknowledge.uky.edu/psychology_gradpub/1

This Article is brought to you for free and open access by the Psychology at UKnowledge. It has been accepted for inclusion in Psychology Graduate Research by an authorized administrator of UKnowledge. For more information, please contact UKnowledge@lsv.uky.edu. 


\section{The Origins of Religious Disbelief: A Dual Inheritance Approach}

\section{Digital Object Identifier (DOI)}

https://doi.org/10.1177/1948550621994001

\section{Notes/Citation Information}

Published in Social Psychological and Personality Science.

(c) The Author(s) 2021

This article is distributed under the terms of the Creative Commons Attribution 4.0 License (https://creativecommons.org/licenses/by/4.0/) which permits any use, reproduction and distribution of the work without further permission provided the original work is attributed as specified on the SAGE and Open Access pages (https://us.sagepub.com/en-us/nam/open-access-at-sage). 


\title{
The Origins of Religious Disbelief: A Dual Inheritance Approach
}

Social Psychological and

Personality Science

I-II

(C) The Author(s) 2021

(c) (i)

Article reuse guidelines:

sagepub.com/journals-permissions DOI: I0.1 I 77//94855062199400 I journals.sagepub.com/home/spp

(S)AGE

\author{
Will M. Gervais' ${ }^{\circ}$, Maxine B. Najle², and Nava Caluori ${ }^{3} \odot$
}

\begin{abstract}
Widespread religious disbelief represents a key testing ground for theories of religion. We evaluated the predictions of three prominent theoretical approaches-secularization, cognitive byproduct, and dual inheritance-in a nationally representative (United States, $N=1,417$ ) data set with preregistered analyses and found considerable support for the dual inheritance perspective. Of key predictors of religious disbelief, witnessing fewer credible cultural cues of religious commitment was the most potent, $\beta=.28$, followed distantly by reflective cognitive style, $\beta=.13$, and less advanced mentalizing, $\beta=.05$. Low cultural exposure predicted about $90 \%$ higher odds of atheism than did peak cognitive reflection, and cognitive reflection only predicted disbelief among those relatively low in cultural exposure to religion. This highlights the utility of considering both evolved intuitions and transmitted culture and emphasizes the dual roles of content- and context-biased social learning in the cultural transmission of disbelief (preprint https://psyarxiv.com/e29rt/).
\end{abstract}

\section{Keywords}

atheism, religion, culture, evolution, dual inheritance theory

Evolutionary approaches to religion have proliferated in recent years, and different theories make starkly different predictions about the existence, nature, and origins of religious disbelief. Atheists - merely people who do not believe in the existence of a God or gods - constitute a large and perhaps growing proportion of earth's human population. A prominent estimate from about a decade ago (Zuckerman, 2007) posits the existence of 500-700 million atheists globally. This estimate is in all likelihood a drastic underestimate (Gervais \& Najle, 2018). People routinely overreport their religious practices (Hadaway et al., 1993), and indirect measurement of atheism in the United States reveals a potentially large gulf between some indirect ( $\sim 26 \%$ ) and direct $(\sim 3 \%)$ estimates of atheist prevalence (Gervais \& Najle, 2018). Combining direct estimates and inferences drawn from the few available indirect estimates, we suspect that upward of 2 billion people on earth may in fact be atheists. Many evolutionary theories of religion posit a universal or near-universal implicit theism (Barrett, 2004, 2010; Bering, 2010; Boyer, 2008) and may thus be fundamentally incompatible with global atheism that is simultaneously prevalent and deliberately concealed. Here, we test predictions on atheism from three prominent theoretical frameworks, as outlined in Table 1: secularization, cognitive byproduct, and an emerging dual inheritance model of religion (Norenzayan \& Gervais, 2013; Norenzayan et al., 2016). This project situates the study of religious disbelief firmly within established theoretical frameworks for studying the evolution of human behavior and contributes to broader discussions of the role of transmitted versus evoked culture in core aspects of human nature (Laland \& Brown, 2011).

\section{Prominent Theoretical Approaches}

Three of the most prominent current approaches to religion and disbelief are secularization theories, the cognitive byproduct approach made popular by evolutionary psychology and the cognitive science of religion, and a dual inheritance approach.

Secularization. Secularization theories emerging from sociology of religion (Inglehart \& Norris, 2004; Marx, 1843; Schnabel, 2020) and social psychology (Inzlicht et al., 2011; Kay et al., 2008) posit that religions serve some sort of societal or intrapsychic function, be it for bringing groups together or assuaging existential concerns. As strong secular institutions emerge in some places (Inglehart \& Norris, 2004) or in situations in which people feel secure and secular institutions can quench a thirst for control and order (Kay et al., 2008), religious motivations

\footnotetext{
'Centre for Culture and Evolution, Brunel University London, Uxbridge, United Kingdom

${ }^{2}$ University of Kentucky, Lexington, KY, USA

${ }^{3}$ University of Virginia, Charlottesville, VA, USA

Corresponding Author:

Will M. Gervais, Centre for Culture and Evolution, Brunel University London, Uxbridge UB8 3PH, United Kingdom.

Email: will.gervais@brunel.ac.uk
} 
Table I. Predictions From Prominent Theories.

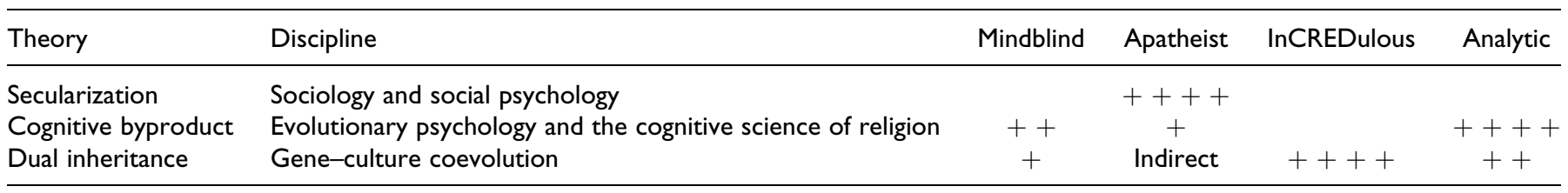

Note. + Symbols indicate the predicted strength of each pathway to atheism by theory. Mindblind = relatively lower in advanced mentalizing; apatheist $=$ relatively more existentially secure; inCREDulous = exposed to relatively fewer religious credibility-enhancing displays; analytic = scoring relatively higher on cognitive reflection.

wane. These approaches predict that religion should be nearly universal but that atheism might emerge when (1) people largely feel existentially secure or (2) secular institutions are strong and effective.

Cognitive byproduct. Cognitive byproduct accounts, emerging from both evolutionary psychology and the cognitive science of religion, view the capacity for religious cognition as a byproduct of adaptations that emerged for other functions (Barrett, 2004; Boyer, 2008). This includes a putative Hyperactive Agency Detection Device — oft posited, never substantiated 41 - and more general mental adaptations for mind perception and social life. The cognitive byproduct approach predicts near-universal theistic belief. Atheism - if indeed, it is a genuine phenomenon rather than a self-report illusion that only goes "skin deep" as some have claimed (Bering, 2010) — would emerge only in special environments and conditions. For example, in this view, atheism could result from subtle individual differences in the cognitive adaptations that underpin the representation of supernatural agents such as mind perception and advanced mentalizing. Alternatively, a common refrain in the cognitive science of religion is that atheism requires effortful cognitive reflection. Prominent scholars of this tradition claim, for example, that atheism "require[s] . . cognitive effort" (Barrett, 2010) and that "disbelief is generally the result of deliberate, effortful work" (Boyer, 2008). Cognitive science of religion researchers repeatedly emphasizes that effortful cognitive reflection underpins atheism. Prominent accounts (Barrett, 2010; Bering, 2010; Boyer, 2008) make the strong predictions that atheism is rare, potentially superficial, and requires cognitive effort. That said, more measured versions of the byproduct account are compatible with a wider range of possible atheist prevalence rates and required levels of cognitive effort. Thus, byproduct accounts from the cognitive science of religion generally predict that atheism may arise, in some cases, through limited mentalizing but (whether or not effort is strictly necessary) that superior analytic thinking is probably the most important predictor of atheism.

Dual inheritance. Some supernatural agent concepts might be cognitively stickier than others by virtue of having contents that are more evocative, memorable, or intuitively compelling (Barrett, 2004; Boyer, 2008). However, it is a far step from mentally representing or remembering a supernatural agent to actually believing in one (Gervais \& Henrich, 2010). To tackle the challenge of belief in (rather than just mental representation of) supernatural agents, work from cultural evolution and gene-culture coevolution has emphasized that religious belief emerges from the interaction of evolved cognitive architecture and cultural learning.

In this view, people are biased to learn some concepts rather than others due to either their contents (some ideas are memorable and evocative) or from the learning context. Several context-dependent learning strategies may be especially important in religious belief and disbelief. Conformist transmission (learning common beliefs; Henrich \& Boyd, 1998), prestigeand success-biased learning (learning from winners; Henrich \& Gil-White, 2001), and behavioral cues diagnostic of underlying beliefs - termed credibility-enhancing displays (CREDs; Henrich, 2009) — combine to powerfully influence what people come to believe or disbelieve. This dual inheritance approach does predict that religious belief will be widespread but also predicts that atheism might naturally result in cultural contexts devoid of consistent behavioral cues that a naive learner ought to believe in any given god (Gervais \& Henrich, 2010; Gervais \& Najle, 2015; Lanman, 2012; Lanman \& Buhrmester, 2017). In a dual inheritance framework, the individual differences in refection or mentalizing highlighted by cognitive byproductists may predict atheism, but cultural cues are probably much more important.

These three broad approaches-secularization, cognitive byproduct, and dual inheritance - make similar predictions about religious belief: namely that it ought to be quite widespread. They make sharply divergent predictions, however, about the nature of disbelief. It is sensible, therefore, to consider the various potential predictors of religious disbelief as a way to contrast the various theories.

\section{Four Pathways to Atheism}

Distinct research trajectories have considered the preconditions for sustained belief in any given god. To currently believe in a god, one (1) must be able to mentally represent gods (Gervais, 2013; Norenzayan et al., 2012; Purzycki \& McNamara, 2016; Willard \& Norenzayan, 2013), (2) must be dispositionally or situationally motivated to believe in some gods (Kay et al., 2008), (3) must receive credible cultural cues that some gods are real (Gervais \& Henrich, 2010; Gervais \& Najle, 2015; Lanman \& Buhrmester, 2017), and (4) must maintain this intuitive belief over time. Tweaks to any of these four components may instead yield disbelief in gods. Separate lines of research partially support this supposition. First, mindblind atheism 
describes the pattern whereby individual differences in advanced mentalizing abilities predict religious disbelief (Norenzayan et al., 2012; Willard \& Norenzayan, 2013) in at least some samples (Maij et al., 2017). Second, apatheism describes the pattern whereby, although people are highly religiously motivated when life is insecure, unstable, and unpredictable, existential security instead predicts reduced religiosity (Inglehart \& Norris, 2004; Kay et al., 2008). Third, inCREDulous atheism describes the pattern whereby a lack of CREDs (Henrich, 2009) that one ought to believe in any gods is a good global predictor of atheism (Gervais \& Najle, 2015; Lanman, 2012). Finally, analytic atheism describes the pattern whereby people who reflectively override their intuitions tend to be less religious than those who "go with their guts" (Pennycook et al., 2016; Shenhav et al., 2012), although the magnitude and consistency of this relation are debatable (Gervais et al., 2018).

\section{Predictions}

Prominent theoretical approaches make subtly diverging predictions about which pathways to atheism (mindblind, apatheism, inCREDulous, or analytic) are most important (see Table 1). First, secularization models (Inglehart \& Norris, 2004; Kay et al., 2008; Vail et al., 2012) posit that increases in existential security (wealth, health, education, etc.) reduce religious motivation. Thus, secularization approaches would predict that measures of existential security and secular institutions (general feelings of safety, faith in police, etc.) ought to be primary predictors of atheism. Apatheism is the most important pathway to disbelief per secularization theories.

Second, cognitive science of religion and evolutionary psychology often view religion as a cognitive byproduct of other mental adaptations (Barrett, 2004; Boyer, 2008) such as mind perception (Gervais, 2013) or predator detection. In this view, challenges in the core cognitive faculties underlying such adaptations (e.g., advanced mentalizing) would predict disbelief, but the primary route to disbelief is people overriding their religious intuitions via effortful cognitive reflection. Analytic atheism is the most important pathway to disbelief per cognitive byproduct theorists.

Finally, dual inheritance models highlight the cultural learning processes (Kline, 2015; Rendell et al., 2011) underpinning religious beliefs (Evans, 2001; Lane et al., 2012; Richert et al., 2017; Willard et al., 2016) and disbelief and largely predict that context-biased social learning - especially CREDs (Henrich, 2009) — would be strongly associated with degrees of religious belief (Gervais \& Najle, 2015). Our dual inheritance approach predicts that CREDs would be most important, followed by other factors such as cognitive reflection, mentalizing, and perhaps existential security. InCREDulous atheism is central to dual inheritance approaches to religious disbelief.

We preregistered a set of analyses to simultaneously evaluate the predictions of secularism, cognitive byproduct, and dual inheritance models, https://osf.io/kfasv, in a probability sample of U.S. American adults. Specifically, we posed three broad questions:
What are the relative predictive contributions of each pathway to atheism when considered simultaneously?

How do the four pathways interact with each other in predicting disbelief?

Does early work on each individual pathway successfully replicate in a nationally representative sample? ${ }^{2}$

To approach these questions, we contracted Growth from Knowledge (GfK) to collect a nationally representative sample of U.S. American adults $(N=1,417)$. Primarily, we were interested in predicting degrees of religious belief and disbelief with measures of (1) advanced mentalizing, (2) existential security, (3) exposure to religious CREDs, and (4) cognitive reflection. For robustness, we tested models using both continuous and dichotomous measures of religious disbelief. We also included a number of demographic and personality covariates to adjust for theory-adjacent but nonetheless documented correlates of religiosity. Full materials, data, and code are available at https://github.com/wgervais/disbelief-origins.

\section{Method}

\section{Sample}

We contracted GfK, which specializes in nationally representative sampling, to gather a probability sample of U.S. American adults. This national probability sample included 1,685 individuals that were broadly representative of the American population in terms of gender $(50.14 \%$ female, $49.51 \%$ male, $0.35 \%$ listing another gender), age $(M=50.58, S D=16.83)$, race/ethnicity, education, census region, household income, homeownership status, and residence within a metropolitan area. ${ }^{3}$ We excluded 268 participants who failed an attention check or who did not complete all measures, leaving a total of 1,417 respondents (see Table 2). Inferences do not appreciably change under alternate exclusion criteria.

\section{Measures}

Religious belief. We tested models with two separate religious disbelief measures. First, we relied on a popular continuous measure of religious belief, the Supernatural Beliefs Scale (Jong et al., 2013), as our main dependent measure of religious belief. This scale was reliable, $\alpha=.95, M=4.91, S D=1.63$. As a robustness check, we also included a binary item in which participants simply indicated whether or not they believe in God.

We also included various other measures of religiosity, which were used to gain a more fine-grained understanding of the demographics of our sample and are summarized in Table 2. For example, we asked participants how often they attended services outside of weddings and funerals and how often they pray. We also asked participants to indicate the religion with which they identify, and they were allowed to select multiple applicable categories (e.g., "atheist" and "agnostic"). We included these variables primarily for descriptive purposes. 
Table 2. Sample Demographics.

\begin{tabular}{lrlr}
\hline Group & $\%$ & Group & $\%$ \\
\hline Education & & Religious identity & \\
<High school & 7.55 & Catholic & 22.94 \\
High school & 27.24 & Evangelical & 38.46 \\
Some college & 28.23 & Jehovah's witness & 1.34 \\
College+ & 36.98 & Mormon & 2.12 \\
& & Jewish & 2.40 \\
God belief & & Muslim & 0.35 \\
Believer & 81.27 & Orthodox & 0.56 \\
Atheist & 18.73 & Hindu & 0.35 \\
& & Buddhist & 0.64 \\
Racelethnicity & & Unitarian Universalist & 1.20 \\
White & 74.45 & Other Christian & 7.41 \\
Black & 8.68 & Other non-Christian & 0.71 \\
Not listed & 4.30 & No religion & 13.27 \\
Multiracial & 10.16 & Atheist & 5.15 \\
Hispanic & 2.40 & Agnostic & 5.29 \\
& & Not listed & 4.73 \\
\hline
\end{tabular}

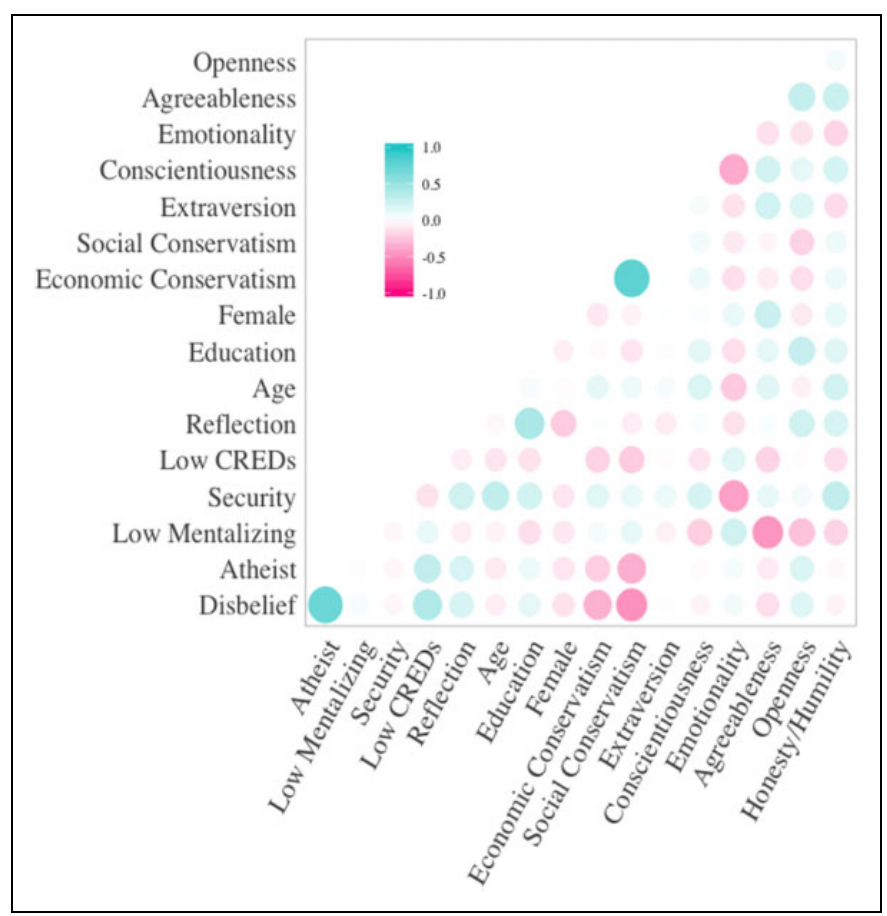

Figure I. Correlation plot of all analyzed variables. Circle size and luminance depict relationship strength, and color depicts positive or negative relationship.

Pathways to religious disbelief. We measured participants' mentalizing abilities, feelings of existential security, exposure to credible cues of religiosity (CREDs), and reflective versus intuitive cognitive style.

We measured advanced mentalizing abilities, which correspond to mindblind atheism, using the Perspective Taking subscale of the Interpersonal Reactivity Index (Davis, 1980). This scale reached an acceptable level of reliability, $\alpha=.77$, $M=4.79, S D=0.78$.
We measured feelings of existential security, which corresponds to apatheism, with a number of items assessing concerns that are salient to participants and participant faith in institutions like the government, health care, and social security to provide aid in the face of need (Willard \& Cingl, 2017). Items measuring faith in institutions were reverse-scored, and all items were averaged together to form a composite index of existential insecurity $(\alpha=.77, M=2.2, S D=0.39)$.

We measured cognitive reflection, which corresponds to analytic atheism, using nine items from the cognitive reflection test (Frederick, 2005; Primi et al., 2016; Toplak et al., 2014). Our full index of cognitive reflection is composed of the sum of the nine questions that each participant answered correctly, with a higher score thus indicating a more reflective and analytic cognitive style. The average score was 3.18 , with an $S D$ of 2.66 .

We measured exposure to CREDs, which corresponds to inCREDulous atheism, with the CREDs Scale (Lanman \& Buhrmester, 2017). This scale assesses the extent to which caregivers demonstrated religious behaviors during the respondent's childhood, such as going to religious services, acting as good religious role models, and making personal sacrifices to religion. This scale was highly reliable, $\alpha=.93, M=2.42$, $S D=0.84$.

Personality measures. We used the Mini-IPIP6 (Milojev et al., 2013) to measure the personality factors of extroversion $(\alpha=.79, M=3.69, S D=1.12)$, agreeableness $(\alpha=.75$, $M=4.96, S D=0.92)$, conscientiousness $(\alpha=.68, M=4.97$, $S D=0.97)$, neuroticism $(\alpha=.75, M=3.52, S D=1.08)$, openness to experience $(\alpha=.73, M=4.69, S D=1.01)$, and honestyhumility $(\alpha=.76, M=4.8, S D=1.13)$.

General demographics. Finally, we included a demographics questionnaire to adjust for known religion-predictive participant characteristics. We assessed education level by asking participants what their highest level of education was, from no formal education to professional or doctorate degree. We used single face-valid items to assess both social $(1=$ very liberal to $7=$ very conservative; $M=4.07, S D=1.77$ ) and economic $(1=$ very liberal to $7=$ very conservative; $M=4.36$, $S D=1.54)$ political ideology.

Correlations. Correlations among all analyzed variables appear in Figure 1 and Table 3.

\section{Results}

\section{Analytic Strategy}

We used Bayesian estimation throughout this study. Bayesian estimation allows us to evaluate the credibility of different parameter estimates, given data and statistical models (Etz \& Vandekerckhove, 2018; Kruschke, 2010, 2013; McElreath, 2016; Wagenmakers et al., 2016). Most analyses report a point estimate reflecting the most credible parameter estimate and 


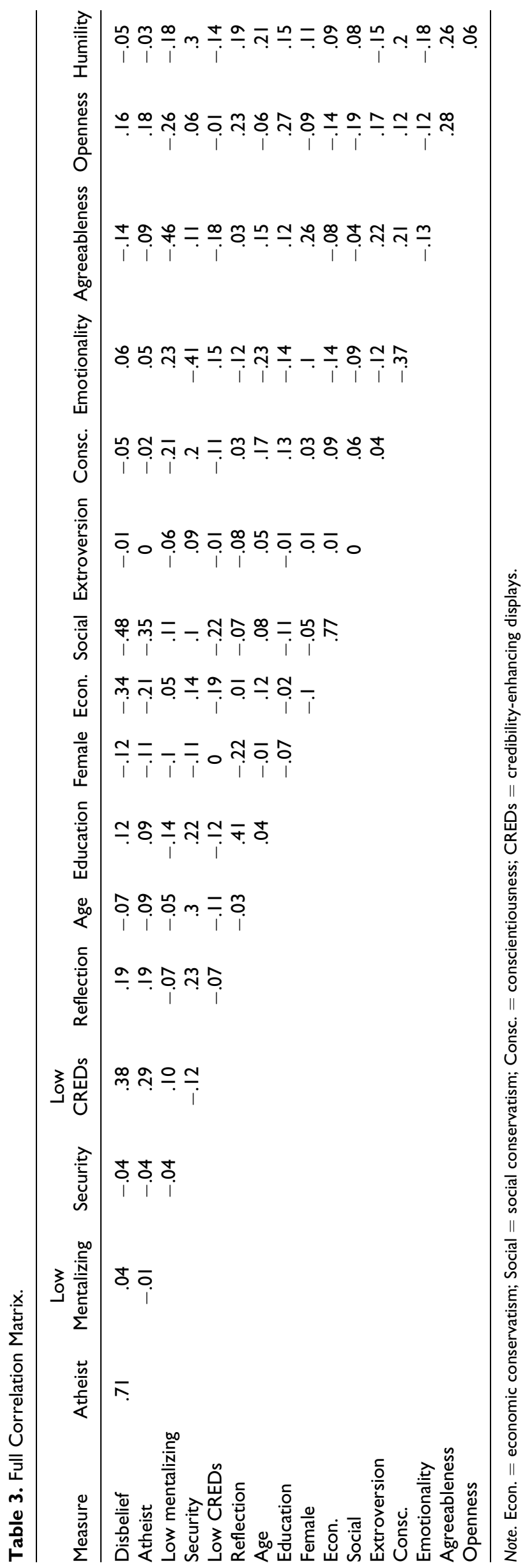


Table 4. Predicting Disbelief: Full Model Summary.

\begin{tabular}{lrrr}
\hline Variable & \multicolumn{1}{c}{ HPDI } & $p(\beta>0)$ \\
\hline Low mentalizing & .05 & {$[-.01, .1 \mathrm{II}]$} & .96 \\
High security & -.02 & {$[-.08, .04]$} & .20 \\
Low CREDs & .28 & {$[.23, .34]$} & $>.99$ \\
High reflection & .13 & {$[.07, .19]$} & $>.99$ \\
Age & .01 & {$[-.04, .07]$} & .67 \\
Education & .04 & {$[-.02, .10]$} & .92 \\
Male & .07 & {$[.02, .13]$} & $>.99$ \\
Social liberalism & .44 & {$[.35, .52]$} & $>.99$ \\
Economic conservatism & .04 & {$[-.04, .12]$} & .84 \\
Extroversion & .02 & {$[-.03, .08]$} & .82 \\
Conscientiousness & .02 & {$[-.04, .07]$} & .72 \\
Neuroticism & 0 & {$[-.06, .07]$} & .54 \\
Low agreeableness & .10 & {$[.04, .17]$} & $>.99$ \\
Openness & .07 & {$[.02, .13]$} & $>.99$ \\
Honesty/humility & .04 & {$[-.02, .10]$} & .92 \\
\hline
\end{tabular}

Note. $\beta=$ standardized coefficient; HPDI $=97 \%$ highest posterior density interval; $p(\beta>0)=$ posterior probability of $\beta>0$; CREDs $=$ credibilityenhancing displays.

the highest posterior density interval (HPDI), the region in which $97 \%$ of most credible estimates lie. We chose $97 \%$ coverage because it is no more arbitrary than any other cutoff but provides a very conservative range of plausible values. We also report a variety of posterior probabilities, which state the probability of something $(\beta>0$, etc.) being true, given data and model. Heuristically, the posterior probabilities have the properties people misintuit frequentist $p$ values as having (e.g., the probability of some hypothesis being true; Oakes, 1986), and the HPDIs have the properties people misintuit frequentist confidence intervals as having (e.g., the probability that a parameter lies in that range; Hoekstra et al., 2014). We used gently regularizing priors throughout, primarily deployed to buffer against model overfitting. Inferences are highly robust to nonludicrous alternative priors. Full materials, data, and code are available at https://github.com/wgervais/disbelief-origins.

\section{Simultaneous Contributions}

Our most important analyses considered the simultaneous contributions of all four pathways operating in concert. As preregistered, we conducted analyses in which the four core factors predict individual differences in belief and disbelief, both in the presence and absence of additional covariates. Multicollinearity among key predictors was not problematic, correlations ranged from $r=-.12$ to .22 . In our full model predicting a continuous multiitem measure of religious disbelief (see Measures section, for details), witnessing fewer credible displays of faith proved to be by far the most powerful predictor of religious disbelief (see Table 4 and Figure 2). CREDs of faith predict belief, and their absence predicts atheism, $\beta=.28,[0.23,0.34]^{4}, p(\beta>0 \mid$ data $)=1 .{ }^{5}$ Cognitive reflection remained a consistent predictor of religious disbelief, $\beta=.13,[0.07,0.19], p(\beta>0 \mid$ data $)=1$, but following earlier cross-cultural work (Gervais et al., 2018), its predictive power was relatively meager. Lower scores on a measure of advanced mentalizing abilities ${ }^{6}$ were reliably but weakly associated with disbelief, $\beta=.05,[-0.01,0.11], p(\beta>0 \mid$ data $)=0.96$, and existential security predicted essentially nothing. Relatively, fewer religious CREDs were the strongest predictor of atheism when all four potential pathways are considered simultaneously.

Atheism: Binary measure. We also measured religious disbelief with a simple binary (no, yes) belief in God item. As a robustness check, we reran our full model analysis as a logistic model predicting atheism rates on the binary measure. Unsurprisingly, results closely matched the continuous full model. Aside from demographic covariates, only fewer religious CREDs, $\beta=.83$, $[0.61,1.05], p(\beta>0 \mid$ data $)=1$, and more cognitive reflection, $\beta=.38,[0.17,0.59]=p(\beta>0 \mid$ data $)=1$, predicted atheism. However, fewer religious CREDs again emerged as a stronger predictor of atheism than did cognitive reflection. To illustrate, we considered the posterior produced by our model, marginalized at various levels of our predictors. Specifically, we compared the hypothetical probability of atheism for model-predicted individuals who are either perfectly in CREDulous (scoring at the floor for religious CREDs) but typical on all other variables or else perfectly analytical (scoring at ceiling on cognitive reflection) but otherwise typical. The predicted odds of atheism are about $90 \%$ higher for a purely inCREDulous individual, $p$ (atheism $\mid$ inCREDulous $)=0.31,[0.24$, 0.39 ], than for a purely analytic individual, $p$ (atheism analytic $)=0.20,[0.13,0.28]$, odds ratio $=1.87,[0.93,3.03]$, $p$ (inCREDulous $>$ analytic $\mid$ data $)=0.99$. This relative difference in predictive strength for CREDs and cognitive reflection, replicated across continuous and binary measures of disbelief, is most consistent with a dual inheritance approach.

\section{Hypothesized Interactions}

Next, we probed for preregistered interactions ${ }^{7}$ finding an interaction between cultural learning and reflective cognitive style, $\beta=-.08,[-0.12,-0.03], p(\beta>0 \mid$ data $)=1$. We considered the association between disbelief and reflective cognitive style among those comparatively high and low on religious CREDs (Figure 3), finding that reflective cognitive style primarily predicts religious disbelief among those who were also comparatively low in cultural exposure to credible religious cues of faith. Indeed, cognitive reflection moderately predicted religious disbelief among those witnessing the fewest religious CREDs, $\beta=.26$, $[0.15,0.35], p(\beta>0 \mid$ data $)=0$, but not at all among those highest in religious CREDs, $\beta=-.01$, $[-0.13$, $0.10], p(\beta>0 \mid$ data $)=0.6$. These patterns highlight the interactive predictive roles of cultural context and evolved intuitions on religious cognition. This interaction is consistent with a dual inheritance perspective but not obviously predicted by other prominent theoretical approaches. 


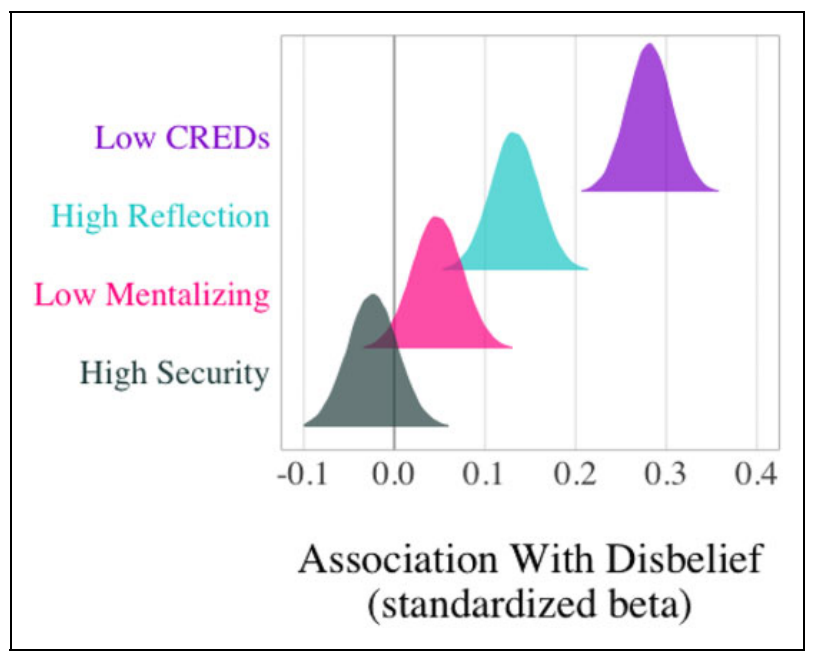

Figure 2. Posterior densities illustrating how strongly each factor predicts disbelief. Height in each density indexes credibility of estimate: Values higher up each curve are better guesses.

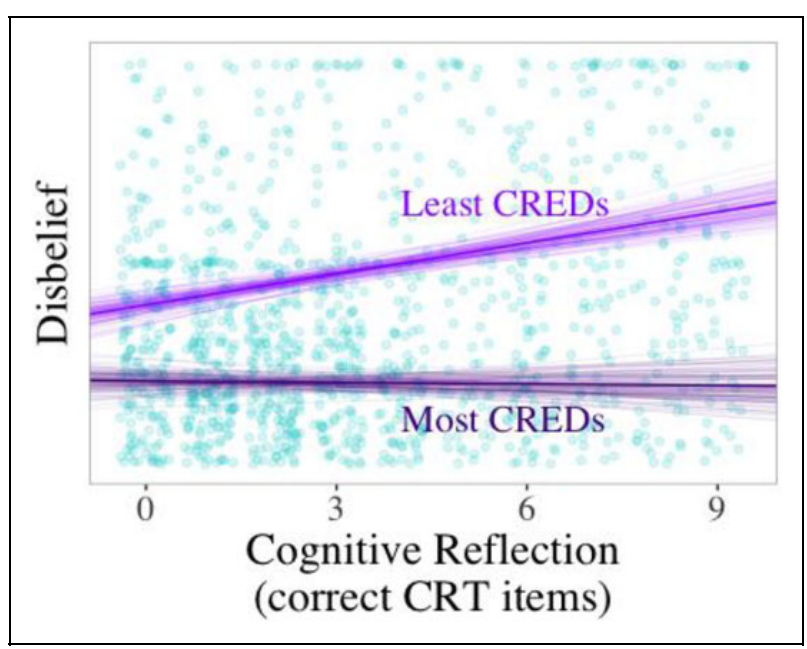

Figure 3. Cognitive reflection primarily predicts disbelief among individuals who are also relatively low in exposure to religious CREDs. Each cluster contains 100 regression lines drawn from the posterior to illustrate estimate uncertainty and regions of the highest posterior density. $Y$-axis depicts the entire range of possible values for the arbitrarily scaled continuous measure.

\section{Discussion}

\section{Summary}

Overall, this study is one of the most comprehensive available analyses of the cognitive, cultural, and motivational factors that predict individual differences in religious belief and disbelief (see also Willard \& Cingl, 2017). Consistent patterns emerged, suggesting that lack of exposure to CREDs of religious faith is a key predictor of atheism. Once this context-biased cultural learning mechanism is accounted for, reflective cognitive style predicts some people being slightly more prone to religious disbelief than their cultural upbringing might otherwise suggest.
That said, this relationship was relatively modest. Advanced mentalizing was a robust but weak predictor of religious belief, and existential security did not meaningfully predict disbelief. This overall pattern of results closely matched predictions of a dual inheritance approach but is difficult to reconcile with other prominent theoretical approaches (see Table 1 and Figure 2). These results speak directly to competing for theoretical perspectives on the origins of religious disbelief culled from sociology, social psychology, evolutionary psychology, cognitive science of religion, cultural evolution, and gene-culture coevolution.

\section{Alternatives and Limitations}

Of the four primary atheism predictors that we used to test prominent theories, religious CREDs emerged as a clear empirical winner. In some ways, however, our tests may have been methodologically stacked in this variable's favor. Like the self-reports of religious disbelief, this measure includes self-report items about religious upbringing. Thus, there is shared method variance associated with this predictor that is less evident for others. Also, although the CREDs-atheism relationship is consistent with a cultural transmission framework, heritability of religiosity may also contribute to atheists coming from families who aren't visibly religious. The measure we used is unable to resolve this. Further, our various key predictors varied in both reliability and demonstrated validity. We chose these measures simply because they have been used in previous research; that said, previous use does not necessarily imply that the measures were sufficient.

As with measurement quality, sample diversity is a recurrent concern in psychological research (Henrich et al., 2010; Rad et al., 2018; Saab et al., 2020). Most psychology research nowadays emerges from convenience samples of undergraduates and Mechanical Turk workers. These samples are fine for some purposes, quite limited for others (Gaither, 2019), and are known to depart from representativeness (Callegaro et al., 2014; MacInnis et al., 2018). While our nationally representative sampling allows us to generalize beyond samples, we can access for free (in lab) or cheap (MTurk), even a large nationally representative sample barely scratches the surface of human diversity (Henrich et al., 2010; Rad et al., 2018; Saab et al., 2020). As such, we encourage similar analyses across different cultures (Willard \& Cingl, 2017). Diversifying the samples that make up the empirical portfolio of evolutionary approaches to religion is especially necessary because cultural cues themselves emerged as the strongest predictor of disbelief in this and related work (Gervais \& Najle, 2015; Gervais et al., 2018; Maij et al., 2017; Willard \& Cingl, 2017). Without diverse samples, including and especially extending well beyond nationally representative samples in the United States, researchers can only aspire to ever more precisely answer a mere outlier of an outlier of our most important scientific questions about human nature.

We measured and tested predictors of religious belief and disbelief. This outcome measure is quite narrow in scope, in 
terms of the broader construct of religiosity. Further, our Supernatural Belief Scale - while it has been used across culturesis fairly Judeo-Christian-centric. We suspect that a broader consideration of religiosity in diverse societies may yield different patterns. The Western, Educated, Industrialized, Rich, Democratic (WEIRD) people problem isn't just a sampling issue; it also reflects an overreliance on the theories, constructs, and instruments developed by WEIRD researchers to test their weird hunches.

Although it is not featured in any of the core theoretical perspectives we evaluated, social liberalism was consistently the strongest covariate of religious disbelief. The intersection of religious and political ideology is an interesting topic in its own right and merits further consideration. Interestingly, disbelief if anything was associated with fiscal conservatism in this sample. This suggests that simple "believers are conservative" tropes are oversimplifications. Ideology and religiosity are multifaceted and dissociable, but certainly of interest given rampant political polarization in the United States and elsewhere. That said, religion-ideology associations, whatever they may be, are largely orthogonal to existing cultural and evolutionary theories of religious belief and disbelief.

\section{Theoretical Implications}

We simultaneously evaluated predictions about the origins of disbelief from three prominent theoretical perspectives: secularization, cognitive byproduct, and dual inheritance. Comparing the predictions in Table 1 with the results of Figure 2, results were most consistent with the dual inheritance perspective, the only theoretical perspective that predicted prominent roles for both inCREDulous atheism and analytic atheism. Given the primacy of cultural learning in our data, any model that does not rely heavily on context-biased cultural learning is likely a poor fit for explaining the origins of religious disbelief. By extension, such theoretical models are necessarily incomplete or faulty evolutionary accounts of religion. Simply growing up in a home with relatively fewer credible displays of faith predicted disbelief, contra prior assertions from the cognitive science of religion that disbelief results from "special cultural conditions" and "a good degree of cultural scaffolding" (Barrett, 2010).

Analytic atheism is probably the most discussed avenue to disbelief in the literature (Pennycook et al., 2016; Shenhav et al., 2012) and broader culture (Dawkins, 2006). Although in this sample, there was consistent evidence of analytic atheism, the overall trend was modest, the trend itself varied considerably across exposure to CREDs, and sufficient religious CREDs buffered believers against the putatively corrosive influence of reflective cognition on faith. Despite claims that atheism generally requires cognitive effort or reflection (Barrett, 2010; Boyer, 2008), cognitive reflection was only modestly related to atheism in these data. These results, taken alongside other evidence accumulating from similar studies (Farias et al., 2017; Gervais et al., 2018; Willard \& Cingl, 2017), may suggest that early claims surrounding the primacy of effortful cognitive reflection as a necessary predictor of atheism may have been overenthusiastic. Analytic thinking predicts atheism in some contexts but is far from primary.

It is initially puzzling that existential security proved largely impotent in our analyses, as it appears to be an important factor in explaining cross-cultural differences in religiosity (Barber, 2013; Inglehart \& Norris, 2004; Solt et al., 2011). It is possible that our analyses were at the wrong level of analysis to capture the influence of existential security, which may act as a precursor to other cultural forces. There may actually be a two-stage generational process whereby existential security demotivates religious behavior in one generation, leading the subsequent generation to atheism as they do not witness CREDs of faith. This longitudinal societal prediction merits future investigation.

Finally, this work has implications beyond religion. Presumably, many beliefs arise from an interaction between core cognitive faculties, motivation, cultural exposure, and cognitive style. The general dual inheritance framework adopted here may prove fruitful for other sorts of beliefs elsewhere. Indeed, a thorough exploration of the degree to which different beliefs are predicted by cultural exposure relative to other cognitive factors may be useful for exploring content- versus context-biased cultural learning and the contributions of transmitted and evoked culture. As this is a prominent point of contention between different schools of human evolutionary thought (Laland \& Brown, 2011), such as evolutionary psychology and cultural evolution, further targeted investigation may be productive.

\section{Coda}

The importance of transmitted culture and context-biased cultural learning as a predictor of belief and disbelief cannot be overstated. Combined, this work suggests that if you are guessing whether or not individuals are believers or atheists, you are better-off knowing how their parents behaved-Did they tithe? Pray regularly? Attend synagogue? - than how they themselves process information. Further, our interaction analyses suggest that sufficiently strong cultural exposure yields sustained religious commitment even in the face of the putatively corrosive influence of cognitive reflection. Theoretically, these results fit well within a dual inheritance approach, as evolved cognitive capacities for cultural learning prove to be the most potent predictor of individual differences in the crossculturally canalized expression of religious belief. Atheists are becoming increasingly common in the world, not because human psychology is fundamentally changing but rather because evolved cognition remains fairly stable in the face of a rapidly changing cultural context that is itself the product of a coevolutionary process. Faith emerges in some cultural contexts, and atheism is the natural result in others.

\section{Authors' Note}

This project was approved by the Office of Research Integrity at the University of Kentucky. https://osf.io/kfasv. 


\section{Acknowledgments}

Sarah Schiavone helped with survey implementation and early data processing but declined authorship; we nonetheless acknowledge and thank her for the work on this article.

\section{Author Contributions}

W.M.G. designed the study, with survey revision and implementation from M.B.N. M.B.N. contributed feedback and piloting throughout the life of this project. W.M.G. performed the primary analyses, and N.C. performed descriptive analyses. W.M.G. wrote the article with N.C. All authors approved the final article.

\section{Declaration of Conflicting Interests}

The author(s) declared no potential conflicts of interest with respect to the research, authorship, and/or publication of this article.

\section{Funding}

The author(s) disclosed receipt of the following financial support for the research, authorship, and/or publication of this article: This research was supported by a grant to W.M.G. from the John Templeton Foundation (48275). N.S. was supported by a National Science Foundation Graduate Research Fellowship. The content is solely the responsibility of the authors and does not necessarily represent the official views of its funders. The funders had no role in study design, data collection and analysis, decision to publish, or preparation of the article.

\section{ORCID iDs}

Will M. Gervais (D) https://orcid.org/0000-0001-7790-1665

Nava Caluori (D) https://orcid.org/0000-0003-1632-4512

\section{Supplemental Material}

The supplemental material is available in the online version of the article.

\section{Notes}

1. Anecdotally, many-to-most graduate students in cognitive science of religion have tried these studies to no avail.

2. Analyses treating each core pathway in isolation rather than in a single combined model are presented in the Online Supplement.

3. Note: Our precise sample demographics may look a bit different from census estimates on, for example, ethnicity or education. Growth from Knowledge provided proper probability sampling for representativeness, but our precise measures were not identical to those used by the census. Apparent discrepancies may be due to differing demographic measures and categories, rather than probability sampling errors.

4. Values in brackets are $97 \%$ highest posterior density interval.

5. $p(\beta>0 \mid$ data $)=1$ indicates a posterior probability exceeding .99 .

6 . We preregistered a possible quadratic relationship between mentalizing and disbelief. For theoretical and statistical reasons, we depart from preregistration and don't analyze the quadratic here. See Online Supplement for further discussion.
7. Preregistered analyses probing for interactions with mentalizing yielded nothing of particular note and are summarized in the Online Supplement.

\section{References}

Barber, N. (2013). Country religiosity declines as material security increases. Cross-Cultural Research, 47(1), 42-50.

Barrett, J. L. (2004). Why would anyone believe in God? AltaMira Press.

Barrett, J. L. (2010). The relative unnaturalness of atheism: On why Geertz and Markusson are both right and wrong. Religion, 40(3), 169-172. https://doi.org/10.1016/j.religion.2009.11.002

Bering, J. M. (2010). Atheism is only skin deep: Geertz and Markússon rely mistakenly on sociodemographic data as meaningful indicators of underlying cognition. Religion, 40(3), 166-168. https://doi.org/ 10.1016/j.religion.2009.11.001

Boyer, P. (2008). Being human: Religion: Bound to believe? Nature, 455(7216), 1038-1039.

Callegaro, M., Villar, A., Yeager, D. S., \& Krosnick, J. A. (2014). A critical review of studies investigating the quality of data obtained with online panels based on probability and nonprobability samples. Online Panel Research: A Data Quality Perspective (pp. 23-53). Wiley.

Davis, M. H. (1980). Interpersonal reactivity index. Edwin Mellen Press.

Dawkins, R. (2006). The God delusion. Houghton Mifflin Harcourt.

Etz, A., \& Vandekerckhove, J. (2018). Introduction to Bayesian inference for psychology. Psychonomic Bulletin \& Review, 25(1), 5-34.

Evans, E. M. (2001). Cognitive and contextual factors in the emergence of diverse belief systems: Creation versus evolution. Cognitive Psychology, 42(3), 217-266. https://doi.org/10.1006/ cogp.2001.0749

Farias, M., van Mulukom, V., Kahane, G., Kreplin, U., Joyce, A., Soares, P., Oviedo, L., Hernu, M., Rokita, K., \& Savulescu, J. (2017). Supernatural belief is not modulated by intuitive thinking style or cognitive inhibition. Scientific Reports, 7, Article 15100. https://doi.org/10.1038/s41598-017-14090-9

Frederick, S. (2005). Cognitive reflection and decision making. Journal of Economic Perspectives, 19(4), 25-42. https://doi.org/ $10.1257 / 089533005775196732$

Gaither, S. (2019). Diversifying psychological science. Psychology Today. https://www.psychologytoday.com/blog/different-identi ties-different-perspectives/201908/diversifying-psychologicalscience

Gervais, W. M. (2013). Perceiving minds and gods how mind perception enables, constrains, and is triggered by belief in gods. Perspectives on Psychological Science, 8(4), 380-394.

Gervais, W. M., \& Henrich, J. (2010). The Zeus problem: Why representational content biases cannot explain faith in gods. Journal of Cognition and Culture, 10(3-4), 3-4.

Gervais, W. M., \& Najle, M. B. (2015). Learned faith: The influences of evolved cultural learning mechanisms on belief in Gods. Psychology of Religion and Spirituality, 7(4), 327.

Gervais, W. M., \& Najle, M. B. (2018). How many atheists are there. Social Psychological and Personality Science, 9, 3-11. 
Gervais, W. M., van Elk, M., Xygalatas, D., McKay, R. T., Aveyard, M., Buchtel, E. E., Dar-Nimrod, I., Klocová, E. K., Ramsay, J. E., \& Riekki, T. (2018). Analytic atheism: A cross-culturally weak and fickle phenomenon? Judgment and Decision Making, 13(3), 268-274.

Hadaway, C. K., Marler, P. L., \& Chaves, M. (1993). What the polls don't show: A closer look at US church attendance. American Sociological Review, 58(6), 741-752.

Henrich, J. (2009). The evolution of costly displays, cooperation and religion. Evolution and Human Behavior, 30(4), 244-260. https://doi. org/10.1016/j.evolhumbehav.2009.03.005

Henrich, J., \& Boyd, R. (1998). The evolution of conformist transmission and the emergence of between-group differences. Evolution and Human Behavior, 19(4), 215-241. https://doi.org/10.1016/ s1090-5138(98)00018-x

Henrich, J., \& Gil-White, F. J. (2001). The evolution of prestige: Freely conferred deference as a mechanism for enhancing the benefits of cultural transmission. Evolution and Human Behavior, 22(3), 165-196. https://doi.org/10.1016/S1090-513 $8(00) 00071-4$

Henrich, J., Heine, S. J., \& Norenzayan, A. (2010). The weirdest people in the world? Behavioral and Brain Sciences, 33(2-3), 61-83. https://doi.org/10.1017/S0140525X0999152X

Hoekstra, R., Morey, R. D., Rouder, J. N., \& Wagenmakers, E.-J. (2014). Robust misinterpretation of confidence intervals. Psychonomic Bulletin \& Review, 21(5), 1157-1164.

Inglehart, R., \& Norris, P. (2004). Sacred and secular: Religion and politics worldwide. Cambridge University Press.

Inzlicht, M., Tullett, A. M., \& Good, M. (2011). The need to believe: A neuroscience account of religion as a motivated process. Religion, Brain \& Behavior, 1(3), 192-212.

Jong, J., Bluemke, M., \& Halberstadt, J. (2013). Fear of death and supernatural beliefs: Developing a new Supernatural Belief Scale to test the relationship. European Journal of Personality, 27(5), 495-506.

Kay, A. C., Gaucher, D., Napier, J. L., Callan, M. J., \& Laurin, K. (2008). God and the government: Testing a compensatory control mechanism for the support of external systems. Journal of Personality and Social Psychology, 95(1), 18.

Kline, M. A. (2015). How to learn about teaching: An evolutionary framework for the study of teaching behavior in humans and other animals. Behavioral and Brain Sciences, 38, e31. https://doi.org/ 10.1017/S0140525X14000090

Kruschke, J. K. (2010). Doing Bayesian data analysis: A tutorial introduction with $R$. Academic Press.

Kruschke, J. K. (2013). Bayesian estimation supersedes the t test. Journal of Experimental Psychology: General, 142(2), 573.

Laland, K. N., \& Brown, G. R. (2011). Sense and nonsense: Evolutionary perspectives on human behaviour. Oxford University Press.

Lane, J. D., Wellman, H. M., \& Evans, E. M. (2012). Sociocultural input facilitates children's developing understanding of extraordinary minds. Child Development, 83(3), 1007-1021.

Lanman, J. A. (2012). The importance of religious displays for belief acquisition and secularization. Journal of Contemporary Religion, 27(1), 49-65.
Lanman, J. A., \& Buhrmester, M. D. (2017). Religious actions speak louder than words: Exposure to credibility-enhancing displays predicts theism. Religion, Brain \& Behavior, 7(1), 3-16.

MacInnis, B., Krosnick, J. A., Ho, A. S., \& Cho, M.-J. (2018). The accuracy of measurements with probability and nonprobability survey samples: Replication and extension. Public Opinion Quarterly, 82(4), 707-744.

Maij, D. L. R., van Harreveld, F., Gervais, W. M., Schrag, Y., Mohr, C., \& van Elk, M. (2017). Mentalizing skills do not differentiate believers from non-believers, but credibility enhancing displays do. PLoS One, 12(8), e0182764. https://doi.org/10.1371/journal. pone. 0182764

Marx, K. (1843). Critique of Hegel's 'Philosophy of right'. CUP Archive.

McElreath, R. (2016). Statistical rethinking: A Bayesian course with examples in $R$ and Stan (Vol. 122). CRC Press.

Milojev, P., Osborne, D., Greaves, L. M., Barlow, F. K., \& Sibley, C. G. (2013). The Mini-IPIP6: Tiny yet highly stable markers of Big Six personality. Journal of Research in Personality, 47(6), 936-944.

Norenzayan, A., \& Gervais, W. M. (2013). The origins of religious disbelief. Trends in Cognitive Sciences, 17(1), 20-25.

Norenzayan, A., Gervais, W. M., \& Trzesniewski, K. H. (2012). Mentalizing deficits constrain belief in a personal God. PLoS One, 7(5), e36880.

Norenzayan, A., Shariff, A. F., Gervais, W. M., Willard, A. K., McNamara, R. A., Slingerland, E., \& Henrich, J. (2016). The cultural evolution of prosocial religions. Behavioral and Brain Sciences, 39, 1-65. https://doi.org/10.1017/S0140525X14001356

Oakes, M. (1986). Statistical inference: A commentary for the social and behavioral sciences. Wiley.

Pennycook, G., Ross, R. M., Koehler, D. J., \& Fugelsang, J. A. (2016). Atheists and agnostics are more reflective than religious believers: Four empirical studies and a meta-analysis. PLoS One, 11(4), e0153039.

Primi, C., Morsanyi, K., Chiesi, F., Donati, M. A., \& Hamilton, J. (2016). The development and testing of a new version of the cognitive reflection test applying item response theory (IRT). Journal of Behavioral Decision Making, 29(5), 453-469.

Purzycki, B. G., \& McNamara, R. A. (2016). An ecological theory of gods' minds. In H. De Cruz \& R. Nichols (Eds.), Advances in Religion, Cognitive Science, and Experimental Philosophy (pp. 143-167). Continuum.

Rad, M. S., Martingano, A. J., \& Ginges, J. (2018). Toward a psychology of Homo Sapiens: Making psychological science more representative of the human population. Proceedings of the National Academy of Sciences of the United States of America, 115(45), 11401-11405. https://doi.org/10.1073/pnas.1721165115

Rendell, L., Fogarty, L., Hoppitt, W. J. E., Morgan, T. J. H., Webster, M. M., \& Laland, K. N. (2011). Cognitive culture: Theoretical and empirical insights into social learning strategies. Trends in Cognitive Sciences, 15(2), 68-76. https://doi.org/10.1016/j.tics. 2010.12.002

Richert, R. A., Saide, A. R., Lesage, K. A., \& Shaman, N. J. (2017). The role of religious context in children's differentiation between 
God's mind and human minds. British Journal of Developmental Psychology, 35(1), 37-59.

Saab, R., Ayanian, A. H., \& Hawi, D. R. (2020). The status of Arabic social psychology: A review of 21 st-century research articles. Social Psychological and Personality Science. https://doi.org/10. 1177/1948550620925224

Schnabel, L. (2020). Opiate of the masses? Inequality, religion, and political ideology in the United States. Social Forces, 99, 979-1012.

Shenhav, A., Rand, D. G., \& Greene, J. D. (2012). Divine intuition: Cognitive style influences belief in God. Journal of Experimental Psychology: General, 141(3), 423.

Solt, F., Habel, P., \& Grant, J. T. (2011). Economic inequality, relative power, and religiosity. Social Science Quarterly, 92(2), 447-465.

Toplak, M. E., West, R. F., \& Stanovich, K. E. (2014). Assessing miserly information processing: An expansion of the cognitive reflection test. Thinking \& Reasoning, 20(2), 147-168.

Vail, K. E., Arndt, J., \& Abdollahi, A. (2012). Exploring the existential function of religion and supernatural agent beliefs among Christians, Muslims, atheists, and agnostics. Personality and Social Psychology Bulletin, 38(10), 1288-1300.

Wagenmakers, E.-J., Morey, R. D., \& Lee, M. D. (2016). Bayesian benefits for the pragmatic researcher. Current Directions in Psychological Science, 25(3), 169-176.
Willard, A. K., \& Cingl, L. (2017). Testing theories of secularization and religious belief in the Czech Republic and Slovakia. Evolution and Human Behavior, 38(5), 604-615. https://doi.org/10.1016/j. evolhumbehav.2017.01.002

Willard, A. K., Henrich, J., \& Norenzayan, A. (2016). Memory and belief in the transmission of counterintuitive content. Human Nature, 27(3), 221-243. https://doi.org/10.1007/s12110-016-9259-6

Willard, A. K., \& Norenzayan, A. (2013). Cognitive biases explain religious belief, paranormal belief, and belief in life's purpose. Cognition, 129(2), 379-391. https://doi.org/10.1016/j.cognition. 2013.07.016

Zuckerman, P. (2007). Atheism: Contemporary numbers and patterns. Cambridge University Press.

\section{Author Biographies}

Will Gervais is a Senior Lecturer at the Centre for Culture and Evolution, Brunel University London. He comes to London via New Zealand, Kentucky, Canada, and Colorado. He studies atheists.

Maxine B. Najle has her Ph. D. in social psychology from the University of Kentucky. She applies her research knowledge to data science and polling at BlueLabs Analytics in Washington, DC.

Nava Caluori is an NSF graduate research fellow working on her doctorate at the University of Virginia.

Handling Editor: William Von Hippel 